\title{
Hibridación, intermedialidad y performance en el cortometraje latinoamericano moderno
}

DOI: https://doi.org/10.22409/pragmatizes.v10i19.40660

\section{Javier Cossalter ${ }^{1}$}

Resumen: Entre mediados de la década del cincuenta y mediados de los años setenta el film breve latinoamericano producido prácticamente al margen de la industria fílmica tuvo un rol fundamental en la renovación del cine dentro de un contexto general de dinamismo y modernización del campo cultural regional. El presente artículo analiza comparativamente un corpus representativo de cortometrajes provenientes de Argentina, Brasil, México, Cuba y Chile durante el período señalado, con el propósito de asentar el carácter moderno de dicha producción audiovisual. Para ello, abordamos los films en función de tres rangos de contraste estrechamente vinculados: la hibridación de los modelos cinematográficos, la intermedialidad entre el cine y diversas disciplinas artísticas, el desvío en la construcción del personaje canónico y la incorporación de lo performático. A partir del estudio de estas tres variables es posible desentrañar las especificidades y los puntos en común en torno a este fenómeno desarrollado en cinematografías con tradiciones heterogéneas.

Palabras clave: Cortometraje; Cine Latinoamericano moderno; Intermedialidad; Estrategias performáticas

\section{Hybridization, intermediality and performance in the modern Latin American short film}

\begin{abstract}
Between the mid-1950s and the mid-1970s, the Latin American short film produced practically outside the film industry played a fundamental role in film renewal within a general context of dynamism and modernization of the regional cultural field. This article comparatively analyzes a representative corpus of short films from Argentina, Brazil, Mexico, Cuba and Chile during the indicated period, with the purpose of establishing the modern sense of this audiovisual production. To do this, we approach the films based on three closely linked contrast ranges: the hybridization of cinematographic models, the intermediality between cinema and various artistic disciplines, the deviation in the construction of the canonical character and the incorporation of the performance. From the study of these three variables it is possible to unravel the specificities and common points around this phenomenon developed in cinematographies with heterogeneous traditions.
\end{abstract}

Keywords: Short film; Modern Latin American Cinema; Intermediality; Performative strategies

\section{Hibridação, intermedialidade e performance no curta-metragem latino-americano moderno}

Resumo: Entre meados da década do cinquenta e meados dos anos setenta, o curta-metragem latino-americano produzido praticamente fora da indústria cinematográfica desempenhou um papel

\footnotetext{
${ }^{1}$ Javier Cossalter. Doctor en Historia y Teoría de las Artes por la Universidad de Buenos Aires, profesor de la Facultad de Filosofía y Letras, Universidad de Buenos Aires - CONICET, Argentina. Email: javiercossalter@gmail.com - https://orcid.org/0000-0001-5660-6704
} 
fundamental na renovação do cinema em um contexto geral de dinamismo e modernização do campo cultural regional. Este artigo analisa comparativamente um corpus representativo de curtasmetragens da Argentina, Brasil, México, Cuba e Chile durante o período indicado, com o objetivo de estabelecer o sentido moderno dessa produção audiovisual. Para isso, abordamos os filmes com base em três faixas de contraste estreitamente ligadas: a hibridação de modelos cinematográficos, a intermedialidade entre cinema e várias disciplinas artísticas, o desvio na construção do caráter canônico e a incorporação da performance. A partir do estudo dessas três variáveis, é possível desvendar as especificidades e pontos comuns em torno desse fenômeno, desenvolvidos em cinematografias com tradições heterogêneas.

Palavras chave: Curta-metragem; Cinema latino-americano moderno; Intermedialidade; Estratégias performativas

\section{Hibridación, intermedialidad y performance en el cortometraje latinoamericano moderno}

\section{Introducción}

A partir de la segunda mitad de la década del cincuenta se vislumbró en América Latina un proceso de transformación y modernización del campo cultural y artístico que se acopló hacia fines de los años sesenta con una creciente efervescencia social y posterior radicalización política. Hacia mediados de los años setenta los sucesivos golpes de Estado y la inestabilidad social que afectaron a los países del territorio determinaron la clausura de una etapa a nivel cultural. En términos de Claudia Gilman es posible analizar este macro-período en la región desde la noción de época, que apunta a desentrañar la "convergencia de coyunturas políticas, mandatos intelectuales, programas estéticos y expectativas sociales" (GILMAN, 2003, p. 36). En este sentido, Latinoamérica experimentó un espíritu compartido de renovación de las diferentes disciplinas artísticas que incluyó el intercambio dinámico entre dichas esferas así como la apropiación de elementos de corrientes foráneas.

En el ámbito del cine este impulso dio paso a la denominada modernidad cinematográfica, ${ }^{2}$ la cual

\footnotetext{
${ }^{2}$ Vinculada a los nuevos cines surgidos en Europa a lo largo de la década del sesenta, la modernidad cinematográfica se sustenta en la conciencia lingüística y la explicitación de las huellas del discurso, operaciones que colocan el centro de atención en los medios expresivos del lenguaje fílmico (MONTERDE, 1996). Los cines latinoamericanos tomaron las bases
} 


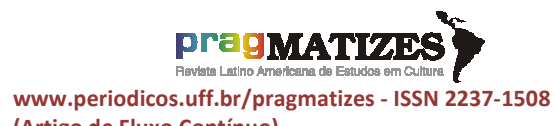

(Artigo de Fluxo Contínuo) se alejaba del modelo industrial hollywoodense en términos productivos, expresivos y semánticos. Espacios alternativos de realización como los talleres, seminarios, escuelas de cine y otras entidades estatales $y$ privadas- posibilitaron una intensa $y$ efectiva exploración estética del lenguaje y del propio dispositivo, en correlato con la puesta reflexiva en imágenes de temáticas marginales, entre ellas, el mundo complejo y heterogéneo de las artes. No obstante, y a pesar de que no todas las cinematografías de la región habían construido una fuerte tradición fílmica industrial, tanto las que habían desarrollado una producción estable Argentina, Brasil y México- como aquellas de producción intermitente Cuba y Chile, por ejemplo- renovaron sus cines a partir de un factor en común: la presencia activa y productiva del cortometraje entendido como un medio de expresión subjetiva.

De este modo, el presente trabajo plantea un análisis comparado de un corpus de films breves latinoamericanos, en tanto representantes de este fenómeno

centrales de este fenómeno para configurar experiencias singulares. plural y heterogéneo durante la etapa abordada, con la intención de examinar tres premisas desplegadas por el cortometraje moderno que en su conjunción evidencian plenamente la renovación del campo cultural en un sentido global e interrelacional: 1) la hibridación de modelos cinematográficos: el desvanecimiento de los lindes entre la ficción, el documental y el cine experimental; 2) la vinculación del cine con otras disciplinas artísticas -el teatro, la literatura, la danza, las artes visuales-: práctica intermedial definida según Irina Rajewsky (2005) como un fenómeno que configura un cruce de fronteras entre medios de distinta naturaleza; 3) un cierto desvío en la concepción psicológica del personaje y la introducción de lo performático como una marca propia de la neovanguardia. ${ }^{3}$ Por tal motivo, organizaremos el artículo en función

\footnotetext{
${ }^{3}$ La cantidad de cortos modernos realizados en los países abordados es extensa y las formas expresivas adoptadas son variadas. No obstante, el corpus de films breves seleccionados articula de forma orgánica las tres variables renovadoras señaladas: Pátio (Glauber Rocha, 1959) -Brasil-, En la noche (Pastor Vega, 1964) -Cuba-, Ana (Helvio Soto, 1965) -Chile-, La creación artística: José Luis Cuevas (Juan José Gurrola, 1965) México- y Grabas (Arnaldo Valsecchi, 1974) Argentina-.
} 
de dichos patrones de contraste, en tanto tres posibles ejes nodales de la modernidad en el cine.

\section{Experimentación en la estructura} del relato: enlaces difusos entre las tipologías fílmicas

La exploración del medio fílmico y sus recursos es una práctica que nació con el cine mismo. En algunos períodos más que en otros el acento puesto en la renovación del lenguaje fue tomado como bandera. Ahora bien, una de las particularidades de la modernidad cinematográfica y las rupturas estético-narrativas que promovió -tanto en Europa como en Latinoamérica- reside en la productividad del cortometraje para desarrollar tales innovaciones. Gracias a sus potencialidades económicas, estéticas y estructurales, el film breve se convirtió en un dispositivo eficaz de experimentación y expresión. ${ }^{4}$ En la región, las condiciones de producción del corto moderno vislumbraron un camino alternativo a la industria cinematográfica de impronta

\footnotetext{
${ }^{4}$ Para profundizar en las particularidades del cortometraje y su eficacia en un contexto de renovación dentro del séptimo arte, véase: Cossalter (2017a, 2017b, 2018a, 2018b).
}

hollywoodense, acogiendo de este modo un rotundo desvío al canon institucionalizado.

En este sentido, los films de corta duración escogidos como parte del corpus de análisis evidencian dicha impronta. El caso más emblemático es el ejemplo cubano, En la noche (Pastor Vega, 1964), puesto que junto con la Revolución de 1959 se puso en marcha desde el Estado un proyecto para instalar una industria del cine moderna que combinara el arte con las prerrogativas políticas de la Revolución, alejada del modelo estético y productivo estadounidense: el Instituto Cubano del Arte e Industria Cinematográficos. Tanto en Chile como en México la universidad tuvo un rol fundamental en la promoción y el sustento del cine moderno. Ana (Helvio Soto, 1965) fue concebido al interior del Centro de Cine Experimental -luego denominado Cine Experimental- de la Universidad de Chile, fundado en 1957; mientras que La creación artística: José Luis Cuevas (Juan José Gurrola, 1965) fue realizado dentro de la Universidad Nacional Autónoma de México, entidad que fomentó las prácticas artísticas renovadores desde la Coordinación de 


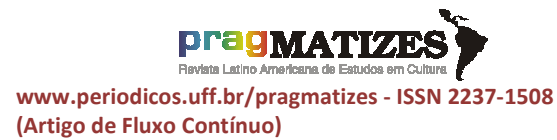

(Artigo de Fluxo Contínuo)
Difusión Cultural de la UNAM. En Argentina, una de las instituciones que más respaldo le brindó al cortometraje moderno -incluso, en torno al tópico del arte- fue el Fondo Nacional de las Artes, un organismo estatal creado en 1958 que dispuso, cuatro años más tarde, un Régimen de Fomento al Cine de Cortometraje. Grabas (Arnaldo Valsecchi, 1974) forma parte de la producción subsidiada por el Fondo en este período. Finalmente, en Brasil, proliferaron para esta época las pequeñas productoras independientes que apostaron a conformar un cine renovador. Este es el caso de Iglu Filmes, constituida en 1958 por los cineastas Braga Neto, Petrus Pires y Paulo Hermida, la cual posibilitó el desarrollo del primer cortometraje de Glauber Rocha, Pátio, en 1959.

De este modo es posible sostener, en términos generales, que las condiciones de producción determinan las formas expresivas abrazadas. En este caso, los canales alternativos permitieron vehiculizar una marcada exploración del lenguaje y de la estructura narrativa que derivó, de manera extrema, en el borramiento de los límites entre las tipologías fílmicas. Es cierto que la ficción, el documental y el cine experimental conllevan consigo ciertos rasgos esenciales así como también es posible hallar préstamos entre estos modelos, los cuales no ponen en duda el estatuto de los mismos. ${ }^{5}$ A los fines de este trabajo, lo interesante surge cuando advertimos un planteo deliberado por disolver y confundir las fronteras entre los modelos, ya sea tomando elementos de uno para poner en escena temas, expresiones y objetivos característicos de otro, o a través de la efectiva hibridación de estos, lo que manifiesta una rotunda autorreflexión del medio y puede derivar en formas cercanas al ensayo.

Pátio presenta, por medio de una causalidad narrativa débil, a un joven y a una muchacha sin siquiera nombres que se entrelazan y relacionan a través de distintos movimientos corporales en un patio cuyo piso comporta la forma de un tablero de ajedrez. La síntesis argumental resulta escueta porque la narración no es el aspecto central que guía el relato, sino que prima su

\footnotetext{
${ }^{5}$ Vicente Benet (1999) explora con detalle las cualidades de cada modelo cinematográfico en su vinculación y distancia con respecto a los demás teniendo como parámetro de referencia a la ficción en tanto tipología hegemónica.
} 
carácter plástico, sensorial y conecta directamente con otras conceptual. En este sentido, la obra combina componentes de la ficción junto a una concepción eminentemente experimental -rótulo manifiesto en los créditos del film-. Por un lado, y en sintonía con los postulados modernos, podríamos distinguir algunos elementos provenientes del cine de arte y ensayo que David Bordwell (1996) teorizó en estrecha ligazón con los nuevos cines europeos de comienzos de la década del sesenta: el relajamiento de la acción, la ausencia de clímax, la explicitación de la interioridad y subjetividad de los personajes, y el movimiento autónomo de la cámara en tanto comentario narrativo abierto. No obstante, la radicalización articulada de las formas expresivas como la ausencia completa de diálogos, la abundancia de primeros planos a fragmentos del cuerpo, tomas cenitales, repetición de encuadres, cámara baja al ras del piso, cambios en el eje y la presencia fundamental del sonido en cuanto elemento expresivo independiente se orienta hacia una propuesta de experiencia sensorial y conceptual que aproxima al corto al ensayo audiovisual y que lo

disciplinas artísticas.

Mediante un enfoque diferente, aunque manteniendo algunas similitudes con el ejemplo brasileño, En la noche también fusiona la ficción dentro de una estructura experimental. ${ }^{6}$ Este corto se centra en una pareja que, en busca de diversión, recorre la noche en La Habana, lo cual dispara una serie de situaciones no concatenadas unas con otras que terminan por vislumbrar el espíritu cultural nocturno de la ciudad. A diferencia de la mayoría de las producciones del ICAIC durante este período, que combinaban la experimentación estética con la difusión en torno al accionar de la Revolución, el film de Pastor Vega se aleja de las prerrogativas políticas para adoptar un estilo abiertamente vanguardista. La pareja se conforma como espectadora de diversos momentos artístico-culturales: un desfile militar, un museo de cuadros pictóricos, el abordaje de una joven en la calle, una obra teatral y un espectáculo de canto. A partir de un

\footnotetext{
${ }^{6}$ El propio director catalogó a esta obra como "un corto dramático experimental" (GARCíA BORRERO, 2007, p. 220).
} 
tono irónico y ambiguo, los personajes comentan las situaciones por medio de gestos, miradas y palabras sueltas sin diálogos-. Asimismo, estos se encuentran inmersos dentro de un entramado narrativo laxo que se erige como una sucesión de cuadros autónomos, sin clímax y donde la presencia de voces en over poemáticas desvía al relato del canon ficcional clásico. En definitiva, la composición espacio-temporal y narrativa así como la configuración del estatuto del personaje acercan al corto a una estructura de corte experimental.

Al igual que en el film cubano, en Ana el modelo cinematográfico de base parecería ser la ficción, aunque se trata más precisamente de una ficción experimental, con el agregado de insertos documentales. A lo largo del relato advertimos distintos momentos escenificados por parte del personaje de Ana, alegóricos y metafóricos, a la par del contexto político y social que vivía la región. Por medio de una puesta en escena singular -tópico que trabajaremos a continuación a propósito de la intermedialidad-, con escaso movimiento escénico y sin diálogos, son las voces en over poéticas y testimoniales que hablan del pueblo, de la miseria, de la libertad, de las torturas y de la solidaridad las que disparan las intervenciones de Ana y de una serie de sujetos que asumirán diversos roles determinados. La ausencia de diálogos, la incorporación de otras voces y la (re)presentación de cuadros autosuficientes son algunos de los elementos que emparentan a estos tres primeros ejemplos donde se rompe con la ficción tradicional; mientras que la concepción de los sujetos-personajes acogerá particularidades distintivas que abordaremos en el último apartado. En este cortometraje, por momentos el relato propone la escenificación de ciertas situaciones relacionadas con la violencia y la efervescencia social. Por otros, este se refiere directamente a la pobreza y a la miseria a través de un montaje dinámico de imágenes fijas documentales de los rostros de los desposeídos mirando a cámara, a la manera de los films políticos más panfletarios que intentan provocar un shock en el espectador apelando a su sensibilidad.

Los representantes mexicano y argentino del corpus parten del documental para acoplar desde allí a 
los otros modelos cinematográficos. La creación artística: José Luis Cuevas está centrado en el artista plástico homónimo, y si bien es catalogado como un documental dentro de la corriente del film sobre arte, su organización interna es más compleja. El registro documental del proceso creativo del pintor y la presencia de sus cuadros se articulan con escenas de índole ficcional y otras semidocumentales; estructura atravesada por procedimientos experimentales. La escena inicial del prólogo resume y anticipa la perspectiva empleada: la imagen es intervenida mediante el viraje a negativo de la misma, en donde un hombre -el propio Cuevascorre dentro de un supermercado hasta que es presuntamente asesinado por una cajera, hecho no corroborado por el congelamiento del fotograma. En este sentido, el corto reúne diferentes situaciones ficcionales en las que el artista participa de acciones solitarias y relaciones interpersonales que dramatizan temas puntuales, los cuales se convierten en esbozos e inspiraciones para sus obras plásticas. De este modo, algunas de ellas se construyen a partir de recursos que ponen en evidencia las huellas enunciativas: la aceleración de la imagen y el cambio de eje de la cámara al poner en escena las obsesiones del artista y sus manías. Pero por otro lado, también contamos con registros semi-documentales de la realidad social que se utilizan como símbolos para sus pinturas. Todas estas imágenes se amalgaman entonces con el acto creativo en sí mismo y el montaje de las obras plásticas gracias a la presencia de una voz en over narradora.

Grabas tampoco se erige como un documental clásico que desarrolla de forma lineal la vida y obra de los artistas reunidos bajo el Grupo Grabas -Delia Cugat, Sergio Camporeale, Pablo Obelar y Daniel Zelaya-. Ahora bien, del mismo modo que en el film anterior, los componentes ficcionales tampoco responden al canon tradicional: no hay una acción dramática en progreso, el relato carece de clímax, los protagonistas asumen un rol particular así como los nexos causales entre las escenas se diluyen, en esta oportunidad mediante una estructura episódica sin lazos en común. Luego de un prólogo que presenta a los artistas prosiguen 
cuatro bloques temáticos -una vista sobre edificios antiguos y modernos; un ciego y dos predicadores; la recolección de basura en la ciudad; el recorrido de una ambulancia de noche- para desembocar en la quinta y última parte, la cual se exhibe como una sumatoria sin lógica alguna de las anteriores. Allí observamos a los artistas en pleno proceso creativo, y una cámara que registra las obras plásticas -como en el corto mexicanopara luego arribar a la última secuencia que mantiene el mismo tenor y que da cuenta del carácter experimental del film: una exposición de cuadros en una galería donde un público ciego se comporta de manera exuberante -trascendiendo el registro de corte documental- y dos personas desnudas que contemplan las obras; acto performático que se halla en sintonía con las manifestaciones de la neovanguardia acaecidas por aquel entonces.

Dinamismo en el campo cultural regional: diálogos fértiles entre las disciplinas artísticas

Los tres patrones de comparación elegidos están íntimamente conectados entre sí, y es justamente la renovación del campo cultural y el dinamismo de las esferas artísticas aquel pilar rector. La hibridación de modelos cinematográficos en tanto innovación estética de la modernidad en el cine da cuenta de ello, como también la apropiación de algunos rasgos de corrientes fílmicas extranjeras marcaría el mismo rumbo. Ahora bien, una de las claves del terreno cultural en este período fue el intercambio fluido entre las diversas prácticas artísticas, en las cuales convergía la intención de modernización. Es por ello que resulta pertinente pensar la región desde el concepto de época (GILMAN, 2003), en tanto conciencia de una sociedad que comparte un horizonte esperado de transformaciones en el campo de la cultura y que determina el discurso de lo deseable. Este proceso de renovación cultural se vio reflejado en el desarrollo de nuevos agentes, la creación de nuevas instituciones, el fortalecimiento de impulsos artísticos novedosos y un nuevo público para estas propuestas (Longoni y Mestman, 2008). De acuerdo a lo expresado, dentro de este contexto primó el contacto directo y productivo entre las 
diferentes tipologías artísticas. En este sentido, la noción de intermedialidad describe con claridad dicho fenómeno; perspectiva teórica que para Óscar Cornago Bernal debe intentar colocar el foco en "los espacios de contacto, diálogo e intercambio entre estas [las tipologías artísticas]" (2004, p. 598). Según Irina Rajewsky, la intermedialidad, en un sentido amplio, puede servir como: "a generic term for all those phenomena that (as indicated by the prefix inter) in some way take place between media" (2005, p. 46). No obstante, desde un enfoque particularizado, la autora distingue tres tipos de relaciones intermediales. En primer lugar incluye la transposición medial. Allí el texto original es la fuente para la conformación de un nuevo producto medial. Se trata de una concepción genética de la intermedialidad. En segunda instancia señala la combinación de medios. En esta, el nuevo producto medial es el resultado de un proceso combinatorio de dos o más medios convencionales. Dichos medios se presentan en su propia materialidad y colaboran en la producción de significado a su modo. Puede establecerse una mera conjunción de medios o una verdadera integración. Finalmente, la tercera variante consiste en la referencia intermedial. Se trata de la tematización, la evocación o la imitación de otro medio y/o sus técnicas, en donde el medio de soporte utiliza sus propios medios para producir sentido. Tanto en la segunda como en la tercera categoría la intermedialidad se configura como un concepto semiótico-comunicacional. Son estas dos variantes las que aparecen con mayor fuerza en el entramado de modernización del campo cultural regional y en el corpus de obras seleccionado para este trabajo, donde tomaremos solamente en cuenta las relaciones intermediales entre el cine y otras artes.

En Pátio el entramado conceptual y poético que sustenta el relato mantiene una relación de referencia intermedial con el movimiento literario concretista, que tuvo sus orígenes en Brasil a mediados de los años cincuenta. Este movimiento de vanguardia en el campo de la poesía fue oficializado por el grupo Noigandres -formado en 1952- de San Pablo en 1956. La poesía concreta buscaba, básicamente, la ruptura con el verso 
como unidad formal a partir de un enfoque racionalista que prestara atención no sólo a la producción de sentido del lenguaje sino que también se ocupara del aspecto materialgráfico -gesto de autorreflexión del medio eminentemente moderno-. De este modo, el carácter visual $-\mathrm{y}$ verbal- de la poesía se colocaba en primer plano a través de una particular disposición de las palabras en el soporte -que incluso podía trascender el medio impreso hacia el video y el multimedia-, la utilización de diferentes colores y tipografías, y la extensión por fuera del papel. En este sentido, recursos como el ideograma signo no lingüístico que representa un concepto-, la estructura verbibocovisual -conjunción de lenguajes que disuelve las fronteras entre la imagen, el sonido y el sentidoy la metacomunicación son los recursos principales que empleaba la poesía concreta, ${ }^{7}$ y que el cortometraje de Rocha se apropió adaptando estas premisas constructivas al lenguaje cinematográfico. El quiebre de la

\footnotetext{
${ }^{7}$ Para profundizar en los postulados de la poesía concreta brasileña revisar las tesis doctorales de Aguilar (2000) y de Souza (2013).
}

narración canónica a través de una causalidad débil y la ausencia de clímax, la falta de diálogos, la intervención marcada del montaje, la puesta en relieve del encuadre y el movimiento autónomo de la cámara junto a la presencia de sonidos disonantes terminan por constituir un entramado verbibocovisual que resalta los componentes materiales de la gramática fílmica: el tiempo, el espacio, el movimiento, el sonido. Asimismo, la fragmentación de los cuerpos de la pareja protagónica, la centralidad de la mímica y los gestos sumado a los intermitentes balbuceos podrían erigirse como ideogramas cuya producción de sentido se vislumbra de forma conceptual y polisémica. Finalmente, bajo la combinación de medios, el arte de la danza también estaría presente de manera intermedial, ya que el movimiento de expresión corporal de los personajes sobre el espacio escénico es el motor significante medular del cortometraje.

Con la Revolución en 1959 Cuba vivió un despertar cultural en términos globales. A la creación temprana del ICAIC le siguieron otras entidades que marcaron un origen. En 
1961 se fundó el Consejo Nacional de Cultura, organismo fundamental del programa cultural de la Revolución, y la Unión de Escritores y Artistas de Cuba (UNEAC), comandada por el poeta Nicolás Guillén, la cual se conformó como un espacio clave para la intelectualidad. Un año más tarde se creó la Escuela Nacional de Arte (ENA), tendiente a la enseñanza en las ramas del ballet, la música, el arte dramático y las artes plásticas. En cuanto a las relaciones intermediales dentro del campo cinematográfico, fue desde "el ICAIC que se promovió una corriente de arte y cultura en un sentido amplio y heterogéneo, siguiendo los lineamientos generales de la Revolución y poniendo el acento en la valorización de lo nacional" (COSSALTER, 2018b, p. 26). Dentro de este contexto sobresalen aquellos cortometrajes donde el foco de atención se coloca en el arte dramático, tal como sucede en el ejemplo del corpus, En la noche. Algunos de estos casos son: Minerva traduce al mar (Oscar Valdés y Humberto Solás, 1962), articulación experimental entre poemas de José Lezama Lima y una danza proferida por dos bailarines frente al mar;
Historia de un ballet (suite yoruba) (José Massip, 1962), registro audiovisual de los ensayos y una puesta en escena llevada a cabo por el Teatro Nacional; Escuela de arte (Bernabé Hernández, 1965), documental en torno a la Escuela de Ballet de las Escuelas Nacionales de Arte de Cubanacán. El film breve de Pastor Vega aquí contemplado mantiene una relación intermedial directa con el teatro, no sólo por medio de la combinación de medios con la inclusión en el relato de una pieza teatral, sino también a través de la apropiación cinematográfica de ciertos recursos de la puesta en escena teatral. $^{8}$ En cuanto a esta última línea podemos apreciar que el uso del blanco y negro, la presencia de una iluminación exigua que conforma un espacio cerrado y autosuficiente, encuadres frontales y el empleo mínimo de movimientos de cámara únicamente para reencuadrar a los personajes- determinan en las

\footnotetext{
${ }^{8}$ Cabe destacar que Pastor Vega había participado hasta el año 1961 del grupo Teatro Estudio creado en 1958, que con el advenimiento de la Revolución asumió un rol destacado para llevar a la escena los problemas sociales imperantes. De allí proviene entonces esta imbricación entre el teatro y el cine en el corto En la noche.
} 
distintas situaciones una composición del cuadro netamente teatral; en compañía con la construcción particular del estatuto de personaje que analizaremos en la última sección de este trabajo. En derredor a los personajes protagónicos, estos se erigen como espectadores de los diferentes momentos culturalesteatrales, y en la obra propiamente dicha se convierten al mismo tiempo en espectadores y actores de esa pieza.

Al igual que el corto cubano, el film chileno evidencia una vinculación estrecha con el teatro y guarda algunas similitudes composicionales con aquel. En relación al contexto de renovación, el cine y el teatro compartieron algunos espacios en común en el país andino: el ámbito universitario. Tal como hemos expresado, el Centro de Cine Experimental fue puesto en marcha en 1957. Este se convirtió, junto al Instituto Fílmico de la Universidad Católica, en un faro de la modernización cinematográfica hasta su cierre con el golpe de Estado de 1973. La transformación teatral chilena comenzó varios años antes de la mano del Teatro Experimental de la
Universidad de Chile en 1941. Un grupo de estudiantes proponía esta renovación a partir de un teatro profesional no comercial, a través de la creación de una escuela de formación, la gestación de un nuevo actor que representara la época y la estimulación de la producción dramática chilena. Asimismo se basó en la difusión del teatro clásico y moderno, y la postulación de nuevos valores. El Teatro Ensayo de la Universidad Católica también reflejó ciertas mutaciones, como por ejemplo la opción por una estética pobre -carente de montajes espectaculares- donde el cuerpo y la actuación se posicionaban en un primer plano. A su vez, debemos sumar a la escena los grupos de teatro independiente, fundamentalmente el ICTUS, fundado a mediados de los años cincuenta, caracterizado como verdadero grupo experimental que indaga en el humor, la sátira, el absurdo, y que hacia mediados de la década del sesenta incorporó el método de la creación colectiva y colocó un mayor peso en la crítica política tomando procedimientos del teatro épico brechtiano. Aquí se destacan las obras de Jorge Díaz. Helvio Soto, director de Ana, tenía una 


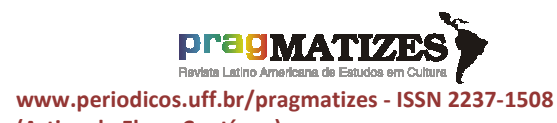

(Artigo de Fluxo Contínuo) afición particular por el teatro y en este film aparecen entrelazados algunos de estos elementos de la renovación. En el corto la puesta en escena funde lo teatral con lo cinematográfico a partir de, principalmente, una combinación de medios, aunque también se produce una referencia intermedial, como en el caso anterior. En este sentido, contamos con un fondo negro que conforma un espacio abstracto e indeterminado en el cual, frente a cámara, se posicionan los personajes, y en donde justamente el cuerpo y la actuación sobresalen. En esta senda, asistimos a distintos tipos y cambios de iluminación, como la penumbra y la oscuridad completa. Asimismo, la utilización de máscaras es un elemento profundamente teatral. Por otro lado, determinados recursos cinematográficos colaboran en la creación de un ambiente teatral y en la focalización exacerbada del gesto corporal del actor: movimientos de cámara poco habituales -circularespara pasar de una situación a otra; encuadres pronunciados primerísimos planos-; la ausencia de parlamentos pero un cierto diálogo entre las voces narrativas y la tenue mímica de Ana; y el empleo reiterado y repetitivo del zoom en ese acercamiento hacia el rostro de la protagonista.

Finalmente, los ejemplos mexicano y argentino no sólo comparten la imbricación del documental y una estructura experimental sino también la disciplina a la cual se abocan: las artes visuales. Lo que sucede en el corto mexicano es interesante, puesto que José Luis Cuevas, el protagonista y figura central del film, era uno de los máximos exponentes de la Generación de la Ruptura en México, movimiento de artistas plásticos que en las décadas del cincuenta y sesenta habían quebrado sus lazos con la Escuela Mexicana de Pintura -representada por el muralismo, su nacionalismo exacerbado y un brío revolucionariopor medio de una ruptura formal sustentada en la abstracción y el neofigurativismo expresivo. Artistas como Alberto Gironella, Vicente Rojo, Lilia Carillo, entre otros, fueron algunos de los referentes de este proceso internacionalista gestado por fuera de los canales oficiales. Es decir, la modernización cultural de las artes plásticas fue contemporánea a la renovación cinematográfica. El cine no 


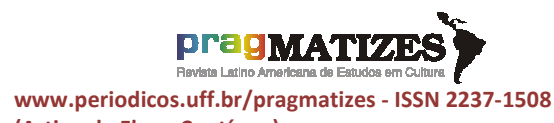

(Artigo de Fluxo Contínuo) sólo tematizó estas innovaciones artísticas sino que en este caso las presentó a partir de una propuesta también innovadora. Por un lado, la intermedialidad entre el cine y la plástica se asienta en la observación del proceso creativo del artista. La creación artística: José Luis Cuevas pone en escena al propio Cuevas en el acto mismo de confección de la obra artística. Lo fílmico y lo plástico se vislumbran como dos fenómenos que se desarrollan de forma paralela y simultánea. Por otro lado, las pinturas y dibujos realizados por el artista conquistan un lugar determinante dentro del relato. A través de un montaje rítmico se suceden las pinturas de manera tal que estas ocupan la totalidad del cuadro fílmico. En este punto, una serie de conceptos pueden ser útiles para aproximarse a la relación intermedial entre estas dos disciplinas. En primer lugar, la noción de cineplástica acuñada por Elie Faure (1956), término que alude tanto a la plasticidad del cine como a la posibilidad de reinventar la plástica gracias a las potencialidades de la cámara. Las técnicas de un medio potencian el sentido producido por el otro. En segunda instancia, y estrechamente conectado con lo anterior, algunos postulados planteados por Pascal Bonitzer (2007) en la correlación entre el cine y la pintura son igualmente pertinentes para analizar estas secuencias del corto: el cuadro, el plano-cuadro y el desencuadre. De este modo, la autosuficiencia del cuadro -en un sentido doble- borra los límites entre el cine y la plástica. Asimismo, la fragmentación de las obras generada por los movimientos de cámara al recorrerlas y los respectivos reencuadres señalan una vez más, y de forma experimental, el fuerte vínculo de asociación que adoptan estos dos medios artísticos en dicho film.

Grabas mantiene algunos puntos en común con el corto mexicano en cuanto a la mostración del proceso creativo y el producto artístico concluido. En esta oportunidad la esfera artística referida es el grabado. El Grupo Grabas, colectivo sobre el cual versa el film, se inserta dentro de la renovación que esta disciplina visual había comenzado a desarrollar desde mediados de los años cincuenta. Otro colectivo visual que tuvo un despliegue análogo en 
este período fue Arte Gráfico-Grupo Buenos Aires, el cual articuló la tradición gráfica con la experimentación. A propósito de este contexto de modernización Silvia Dolinko expresa que: "el grabado argentino de los sesenta sostuvo una ruptura o discusión con su propio canon, transitando por un inédito nivel de experimentación en relación con sus convenciones y parámetros históricos, renovando y cuestionando los estatutos de la imagen gráfica, sus posibilidades técnicas, sus poéticas, sus vías de difusión" (2012, p. 13). El recurso del collage, la abstracción y la intención de trascender los lindes del marco tradicional constituyen las cualidades medulares de este nuevo grabado. Ahora bien, estos mismos rasgos se trasladan a la relación intermedial entre el cine y el grabado en el corto de Valsecchi. En este sentido, se establece en primer lugar una referencia intermedial, ya que se imitan técnicas de un medio -el grabado- a través de procedimientos de otro medio -el cine-. De acuerdo a lo señalado con anterioridad, la estructura del film es episódica y se conforma como un collage de elementos bien heterogéneos. En cuanto al contenido semántico de estos bloques, si bien no se constituyen explícitamente desde la abstracción, las relaciones asociativas ilógicas generan un entramado de difícil comprensión. A su vez, la exposición final de corte performática puede analizarse bajo esta línea de creación estética por fuera de los límites del marco. Por otra parte, la intermedialidad a través de la combinación de medios caracteriza a las escenas que apuntan a visibilizar tanto el proceso creativo como la obra plástica. En el quinto episodio los cuatro artistas se encuentran en el taller, y el acto creativo se exhibe de forma experimental. "Al comienzo, cada uno se halla en una situación autónoma. Después, todos combinan sus tareas en una actividad conjunta la cual se repite con pequeñas variaciones: cambia el motivo del grabado, el sujeto que maneja la máquina, la persona que cuelga los grabados, quien descansa fumando un cigarrillo" (COSSALTER, 2017a, p. 16). Luego, al igual que en el film mexicano, el encuadre y el montaje son los procedimientos cinematográficos centrales para poner en escena a las obras artísticas. En 
principio, la cámara efectúa un paneo sobre los grabados de contenido abstracto que surgieron como resultado del proceso creativo mostrado. Finalmente, presenciamos un montaje de diversas obras, las cuales conquistan el cuadro fílmico en su completitud.

\section{Desintegración del estatuto del} personaje canónico: de la opacidad a lo performático

El tercer y último rango de contraste está directamente vinculado a los otros dos. La ruptura con respecto a la concepción tradicional del personaje responde, por un lado, a la hibridación de los modelos cinematográficos, puesto que no es lo mismo el personaje en la ficción que en el documental y mucho menos en estos productos mixtos; y por el otro, al contexto intermedial, a través de la incorporación de una actitud performática -práctica artística propia de la neovanguardia en desarrollo durante los años sesenta y característica nodal del teatro posdramático (LEHMANN, 2002)-. En este sentido, aquello que se desprende de dicha praxis es la centralidad del cuerpo del actor. Como

bien señala Alicia Aisemberg: "ya no se concibe al actor como representante sino como un productor de presentaciones, por lo cual el acento se coloca en la presencia material y en la dimensión corporal" (2016, p. 27). No obstante, surge un interrogante a partir del análisis del corpus audiovisual contemplado. Las transformaciones en el estatuto de personaje que podemos vislumbrar, ¿derivan de una ruptura con las formas de actuación de corte realista o simplemente se trata de una construcción que se enmarca dentro de un entorno narrativo-expresivo experimental y no convencional al que se suma el gesto paradójico del registro audiovisual de lo performático en tanto carácter irrepetible? Quizás ambas variables estén presentes en distintos matices.

Con el objeto de enriquecer el análisis de este parámetro en los cortometrajes modernos latinoamericanos tomamos algunas de las reflexiones que propone Karina Mauro acerca del realismo, la actuación teatral y sus particularidades en el campo del cine. ${ }^{9}$ En el teatro

\footnotetext{
${ }^{9}$ En torno a este tópico se recomienda la lectura de: Mauro (2014, 2015, 2016 y 2017).
} 
realista, "el personaje pasará a ocupar el lugar central como fundamento de la verosimilitud (y por ende, de la transparencia de la representación). El personaje adquiere entonces características como entidad biográfica ficticia, provista de vida pasada y presente, de rasgos físicos y psicológicos precisos" (MAURO, 2017, p. 530). Estas premisas se trasladan de modo análogo a la ficción cinematográfica tradicional de características similares. No obstante, en los films breves del corpus la ficción no se presenta de forma pura, esta se desvía del canon tradicional y la puesta en escena abandona la transparencia enunciativa. En esta senda, el personaje no configura una composición psicologista que reduzca al mínimo su carácter autorrepresentativo, pero no por ello deja de ser necesariamente una actuación de corte realista. Es cierto que, de algún modo, en todos estos ejemplos el enunciador externo se manifiesta como un partícipe explícito en la construcción de los personajes y que no siempre hay una indiferencia o atenuación del actor ante el dispositivo técnico -postulados que rompen con el naturalismo- (MAURO, 2014). El punto clave reside en la capacidad de disociar una actuación de índole realista de un efecto de carácter realista. Como bien señala la autora: "un enunciado puede percibirse como realista (es decir, poseer un efecto de sentido tal) aun cuando sus elementos constructivos o el tipo de actuación empleado no se correspondan estrictamente con los postulados del realismo como género 0 de la metodología stanislavskiana. Lo cual también admite la aseveración inversa" (MAURO, 2017, p. 528). Es decir que, bien podemos hallar una actuación realista de la mano de la conformación de un personaje opaco dentro de una propuesta experimental que se aleja de la norma. $O$ asistir, como en algunos de los cortos abordados, a una alternancia de diversas posiciones actorales dentro de una misma estructura enunciativa. Por último, una característica distintiva de la actuación cinematográfica con respecto a la teatral le aporta un grado más de complejidad a la relación que se establece entre la actuación, el personaje y la puesta en escena. Nuevamente en palabras de Mauro: "en el cine es el director quien terminará de construir la actuación a 
partir de la manipulación del material obtenido en la situación de actuación, esgrimiéndose por consiguiente como el mediador entre la acción actoral y la actuación" (2016, p. 14). En el terreno cinematográfico la mediación que ejercen el director y la cámara, así como la injerencia ineludible del montaje, ofrecen un abanico singular de posibilidades para organizar los vínculos entre el actor, el personaje y el entorno en el que se insertan. En este sentido, encontramos en el corpus distintos niveles a propósito del estatuto de personaje que rompen con la concepción psicológica tradicional y que responden a esta reflexión y experimentación moderna en términos generales.

En Ana, la puesta en escena es discontinua, tiene interrupciones -se trata de una sucesión de situacionesy en este marco no se atenúa por completo la presencia del actor. Sin embargo, no alcanza a ser performático. Por un lado, contamos con el personaje de Ana que se mantiene casi estática en ese espacio abstracto, con poca gestualidad, cierta inexpresividad y sin diálogos; pero que a pesar de erigirse como una entidad opaca cuyos rasgos psicológicos no se exhiben con claridad, se ofrece en tanto un personaje con una dimensión representacional, que escenifica de forma alegórica diversas problemáticas políticas de la región. Por el otro, emergen diferentes sujetos que se manifiestan bajo la condición de roles -sacerdotes, monjas, un fusiladocuyas acciones, al igual que las desplegadas por Ana, cobran sentido a partir del discurso de las voces narradoras. Son entonces actuaciones realistas que componen personajes desviados del modelo tradicional en un relato híbrido y autorreflexivo donde el cine dialoga estrechamente con el arte teatral. De un modo similar se revelan los personajes centrales de En la noche. Al igual que en el corto chileno, aquí la pareja protagónica transita por diversas situaciones -en este caso culturales- en espacios propiamente teatrales y en otros donde la puesta en escena evidencia una atmosfera teatral. Sin diálogos convencionales con la sola presencia de voces en over que materializan sus pensamientosellos se configuran en tanto personajes-espectadores hasta que, en un gesto autorreflexivo y metatextual, se convierten en personajes-actores de la obra a la cual 
asisten. No obstante estas particularidades, la actuación empleada es netamente realista.

En los ejemplos mexicano y argentino, que combinan el documental con el cine experimental, podemos observar otras modalidades tanto de actuación como del estatuto de personaje. La creación artística: José Luis Cuevas deja entrever dos tipos de construcción alternas. En primer lugar, sobresale el carácter performático del propio Cuevas en el acontecimiento mismo de la creación artística y su registro documental -él pintando-. Es entonces el artista en tanto artista el que pone el cuerpo y se presenta en lugar de representar, aunque como hemos expresado anteriormente la mediación que supone el dispositivo cinematográfico y su capacidad de modular y fijar el acto en imágenes despoja al evento performático de su carácter efímero e irrepetible. En segunda instancia, Cuevas lleva adelante, durante otros pasajes del relato, distintas dramatizaciones de manera inexpresiva. Si bien sigue siendo el artista el que ejecuta dichas acciones y no emula ser un personaje otro, estas escenas aluden a cuestiones metafóricas que se erigen como inspiraciones para su obra plástica -es decir, un signo que está en lugar de otra cosa-, por lo que se encuentran más cerca del polo representacional que de la presentación pura. En Grabas también se disponen y articulan distintas concepciones. En una estructura completamente fragmentaria y experimental apuntamos tres tipologías que vislumbran un entramado complejo y ambiguo. En principio, los predicadores y el ciego que forman parte del núcleo central del segundo bloque del film podrían entenderse como actos performáticos que tienen lugar en las calles de la ciudad puesto que la propuesta del corto se encuentra en sintonía con el clima neovanguardista-. Sin embargo, resulta igualmente pertinente una lectura contrapuesta: que estos sujetos no sean más que personajes construidos específicamente para el relato audiovisual bajo una apariencia presentacional. Luego, los recolectores de residuos que aparecen en el tercer episodio pueden configurarse como personajes documentales, aunque cabe la posibilidad de, como en el caso anterior, cuestionar dicho 
estatuto. En tercera posición ubicamos a los artistas protagonistas de este film breve. Del mismo modo que en el corto mexicano, aquí los grabadores son mostrados en el acto performático de la creación, aunque en este caso el proceder repetitivo y mecánico con el que despliegan su arte, junto con la ya mencionada función mediadora del artificio cinematográfico, podrían sembrar dudas al respecto. Por último, el evento performático final en el museo presenta similitudes con la primera posición, puesto que si bien se trata de una exposición de grabados de los artistas-protagonistas del corto la apariencia y el comportamiento de los supuestos performers permite colocar a la escena tanto en el polo de la representación como en el de la presentación.

Finalmente, en Pátio los personajes se construyen desde una actuación realista y si bien les adjudicábamos a ellos y a la estructura narrativa algunas de las cualidades del cine de arte y ensayo, lo cierto es que el despojamiento general resulta tal que el estatuto de personaje pareciera alejarse del polo representacional. La muchacha y el joven no poseen nombres, no exhiben una psicología definida, y a diferencia de En la noche, en este corto de Rocha los personajes no ostentan acciones concretas dentro de una progreso ficcional que precise un verosímil particular, sino que simplemente son dos cuerpos cuyos movimientos expresivos entran en contacto. La propuesta conceptual y poética del relato se imbrica con el gesto performático de estos cuerpos en constante mutación, determinando un modo singular de constituir el estatus del personaje, el cual se aparta de las fórmulas tradicionales de la ficción.

\section{A modo de conclusión}

En el presente trabajo hemos llevado a cabo un análisis comparado de un corpus representativo de cortometrajes

latinoamericanos producidos entre mediados de la década del cincuenta y mediados de los años setenta, en el contexto de renovación del campo cultural regional, con el propósito de asentar el carácter moderno de dicha producción audiovisual. Para ello, hemos escogido tres rangos de contraste que se erigen en tanto tres parámetros de innovación estética, los cuales en su articulación evidencian un talente profundamente 
rupturista y modernizador que da cuenta de un fenómeno de época que vincula de forma estrecha al terreno cinematográfico con las diversas esferas artísticas dentro de un universo cultural dinámico y transformador. Tanto la hibridación de los modelos cinematográficos -la imbricación entre la ficción, el documental y el cine experimental-, como la práctica intermedial -el cruce de fronteras entre el cine y otros medios artísticos como el teatro, la literatura, las artes visuales y la danza- y la ruptura del estatuto de personaje tradicional -ya sea minimizando y opacando la concepción psicológica o introduciendo el aspecto performático- comportan un componente netamente reflexivo, rasgo primordial de la modernidad. Estos tres elementos ponen en discusión los cánones convencionales, llevando al límite las normas narrativas, estéticas y de puesta en escena tradicionales. Asimismo, estas variables están profundamente conectadas entre sí. La mezcla de tipologías fílmicas pretende romper con la productividad de los géneros y la asociación de un determinado modelo con una función artística o comunicacional específica, y responde al contexto de un campo cultural interrelacional y móvil. Justamente la intermedialidad es una de las cualidades distintivas del ámbito cultural en este período, en donde se quiebra la especificidad de las esferas artísticas para pensar un trazado reticular en el cual conviven disciplinas heterogéneas cuyos intercambios visibilizan innumerables puntos en común. Finalmente, el desvío de la concepción psicológica del personaje y el acercamiento hacia una actitud performática devienen tanto de la hibridación de los modelos -es un personaje que debe hallar su lugar en la intersección de tipologías con lógicas diversas- como del panorama de intermedialidad en el que se inserta con claridad lo performático, que surge en el entramado neovanguardista de la época.

Las cinco cinematografías abordadas, que vislumbran trayectorias heterogéneas, acogieron al cortometraje en tanto medio expresivo renovador al interior de, mayoritariamente, espacios de realización al margen de la industria fílmica y su modelo estético canónico. Es precisamente este contexto de 
COSSALTER, Javier Hibridación, intermedialidad y performance en el cortometraje latinoamericano moderno. PragMATIZES - Revista LatinoAmericana de Estudos em Cultura, Niterói/RJ, Ano 10, n. 19, p. 274-297, set. 2020.

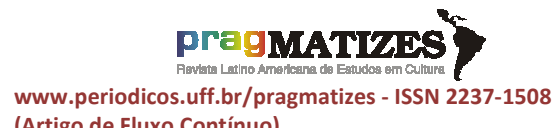

(Artigo de Fluxo Contínuo) producción, junto con las potencialidades económicas y estructurales del film breve, que posibilitaron articular de forma innovadora en el cortometraje las tres aristas modernizadoras analizadas. La experimentación pura y la reflexión radical dentro del audiovisual encuentran en el film de corta duración alternativo un dispositivo eficaz para su desarrollo. El estudio de un corpus más amplio de cortos latinoamericanos modernos permitiría incorporar a la perspectiva adoptada otras variables renovadoras, así como reparar en nuevas relaciones vinculares dentro del campo artístico y cultural del período.

\section{Referencias bibliográficas:}

AGUILAR, Gonzalo. Poesía concreta brasileña. Las vanguardias en la encrucijada modernista. (Doctorado en Letras). Universidad de Buenos Aires, 2000.

AISEMBERG, Alicia. El problema de la representación en las obras de Federico León: cine, teatralidad y performance. Imagofagia, Buenos Aires, n. 14, p. 1-28, 2016.

BENET, Vicente José. Un siglo en sombras. Introducción a la historia y la estética del cine. Valencia: Ediciones de la Mirada, 1999.
BONITZER, Pascal. Desencuadres. Cine y pintura. Buenos Aires: Santiago Arcos Editor, 2007.

BORDWELL, David. La narración en el cine de ficción. Madrid: Paidós, 1996. p. 205-233.

CORNAGO BERNAL, Óscar. El cuerpo invisible: teatro y tecnologías de la imagen. Arbor, Castilla, CLXXVII, n. 699-700, p. 595 - 610, 2004.

COSSALTER, Javier. El cortometraje latinoamericano moderno. Experimentación estética y vínculos con el campo cultural en Argentina, Cuba y México. Anales del Instituto de Investigaciones Estéticas, Ciudad de México, vol. 40, n. 113, p. 9-39, 2018a.

COSSALTER, Javier. El Fondo Nacional de las Artes y el cortometraje argentino. Modernización cultural y estética. Sociohistórica, La Plata, n. 40, 2017a.

COSSALTER, Javier. Experimentación e innovación en el cortometraje documental latinoamericano moderno: las experiencias de Brasil, Cuba y México. Kamchatka. Revista de análisis cultural, Valencia, n. 10, p. 489-511, 2017b.

COSSALTER, Javier. La productividad del cortometraje en la modernidad cinematográfica. El caso argentino. Iberoamericana. América Latina España - Portugal, Berlín, vol. 18, n. 68, p. 141-166, 2018b.

DOLINKO, Silvia. Arte plural. El grabado entre la tradición y la experimentación 1955-1973. Buenos Aires: Edhasa, 2012.

FAURE, Elie. La función social del cine. Buenos Aires: Ediciones Leviatan, 1956. 
COSSALTER, Javier Hibridación, intermedialidad y performance en el cortometraje latinoamericano moderno. PragMATIZES - Revista LatinoAmericana de Estudos em Cultura, Niterói/RJ, Ano 10, n. 19, p. 274-297, set. 2020.

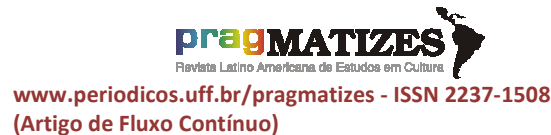

(Artigo de Fluxo Contínuo)
GARCÍA BORRERO, Juan Antonio. Cine cubano de los sesenta: mito y realidad. Madrid: Libros de ultramar, 2007.

GILMAN, Claudia. Entre la pluma y el fusil. Debates y dilemas del escritor revolucionario en América Latina. Buenos Aires: Siglo Veintiuno Editores Argentina, 2003.

LEHMANN, Hans-Thies. Le Théatre postdramatique. París: L'Arche, 2002.

LONGONI, Ana; MESTMAN, Mariano. Del Di Tella a "Tucumán Arde". Vanguardia artística y política en el 68 argentino. Buenos Aires: Eudeba, 2008.

MAURO, Karina. Actuación cinematográfica y análisis teórico. European Review of Artistic Studies, Vila Real, vol. 5, n. 2, p. 43-59, 2014.

MAURO, Karina. Apuntes sobre una cuestión pendiente: la actuación cinematográfica. Imagofagia, Buenos Aires, n. 13, p. 1-25, 2016.

MAURO, Karina. Consideraciones teóricas sobre la actuación cinematográfica. El arte del actor entre el dispositivo cinematográfico y las condiciones de producción. In: Actas $X$ Jornadas Nacionales de Investigación en Arte en Argentina y América Latina. La Plata: Universidad Nacional de La Plata, 2015.

MAURO, Karina. La Metodología de Actuación Realista como Dispositivo de Atenuación de la Presencia del Actor en Teatro y Cine. Revista Brasileira de Estudos da Presença, Rio Grande do Sul, vol. 7, n. 3, p. 523-550, 2017.

MONTERDE, José Enrique. La modernidad cinematográfica. In: Historia General del Cine. Madrid:
Ediciones Cátedra S. A., Vol. IX, Europa y Asia, 1996. p. 15-45.

PARANAGUÁ, Paulo Antonio. Tradición y modernidad en el cine de América Latina. Madrid: FCE, 2003.

RAJEWSKY, Irina O. Intermediality, Intertextuality, and Remediation: A Literary Perspective on Intermediality. Intermédialités, Montréal, n. 6, p. 4364, 2005.

SOUZA, Leandro Cândido de.. Estética Noigandres: vanguardismo e antimimese no projeto concretista (1952-1964). (Doutorado em História). Pontifícia Universidade Católica de São Paulo, 2013. 